\title{
Influence of the single EGR valve usability on development of the charge directed to individual cylinders of an internal combustion engine
}

\author{
Konrad Krakowian ${ }^{1, *}$, Andrzej Kaźmierczak ${ }^{1}$, Aleksander Górniak ${ }^{1}$, and Radosław Wróbel ${ }^{1}$ \\ ${ }^{1}$ Wrocław University of Science and Technology, Faculty of Mechanical Engineering, ul. Braci \\ Gierymskich 164, Wrocław 52-640, Poland
}

\begin{abstract}
Exhaust gas recirculation systems (EGR), aside to a catalytic converters, are nowadays widely used in piston internal combustion engines to reduce nitrogen oxides $\left(\mathrm{NO}_{\mathrm{x}}\right)$ in the exhaust gas. They are characterized in that a portion of exhaust gases from the exhaust manifold is recirculated (via a condenser), and directed to a particular valve. The valve, depending on the current engine load and speed, doses the appropriate amount of exhaust gas into the exhaust manifold. Moreover, its location has a significant impact on the diverse formation of nitrogen oxides and fumes smokiness from the individual cylinders of the engine, which is a result of uneven propagation of exhaust gas into the channels of the intake manifold. This article contains the results of numerical characterized charges formed in symmetrical intake manifold with a centrally-placed EGR valve. Simulations were performed for the original intake system derived from the two-liter, turbocharged VW diesel engine.
\end{abstract}

\section{Introduction}

One of the most difficult problems posed to engineers designing internal combustion engines is to meet stringent emission standards set by the environmentalists. This is due to the fact that road transport has a dominant share in toxic emissions, in particular emission of nitrogen oxides, carbon oxides and hydrocarbons. In order to reduce pollution a further restrictions specifying the permissible limits on the level of toxicity of exhaust gases are continuously introduced. In Europe, they are represented by so-called. EURO standards. Fig. 1 shows how a subsequent EURO standards contributed to a reduction in emissions of mainly $\mathrm{NO}_{\mathrm{x}}$ and PM. It has necessitated the producers to intervene in engine design, combustion process as well as utilization of an additional equipment for exhaust gas treatment.

\footnotetext{
${ }^{*}$ Corresponding author: konrad.krakowian@pwr.edu.pl, aleksander.gorniak@pwr.edu.pl, radoslaw.wrobel@pwr.edu.pl
} 


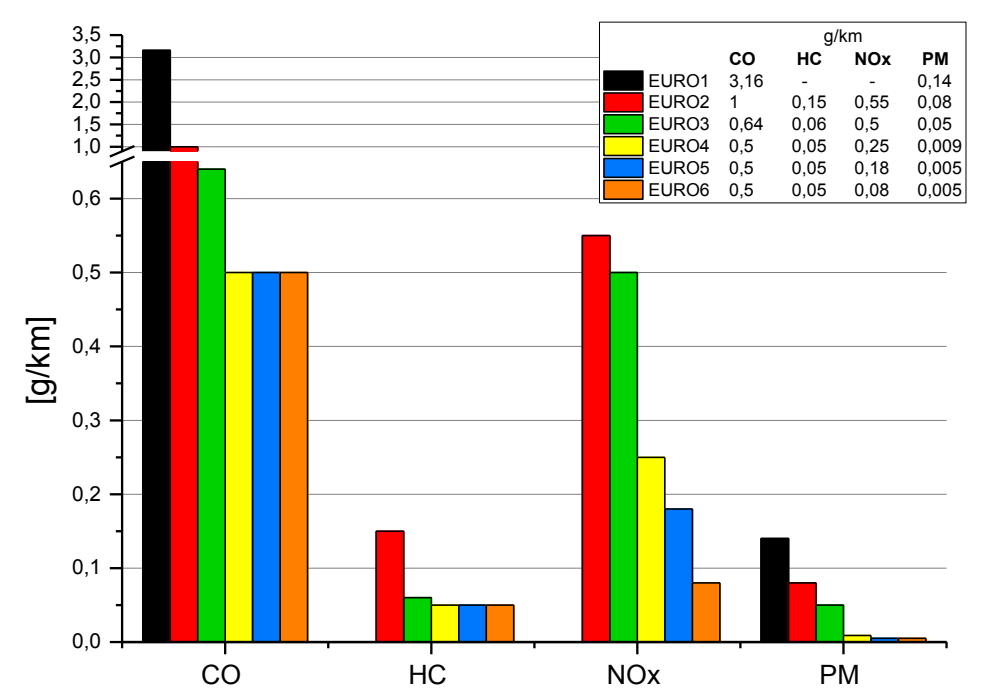

Fig. 1. Changes of allowable exhaust emission limits of subsequent EURO standards.

Designing new engines must involve a reduction of toxic emissions and fuel consumption. Currently in SI engines the reduction of exhaust emissions is achieved by the use of [1]:

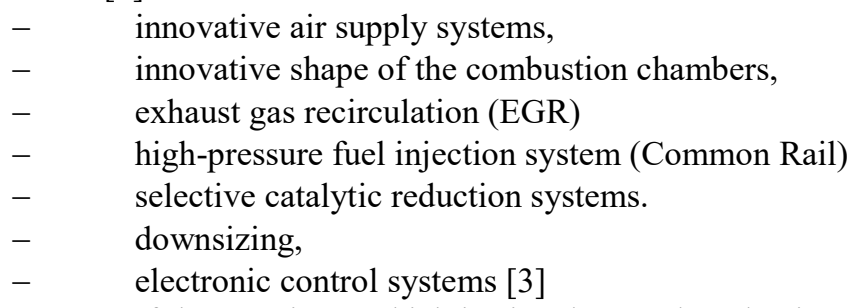

One of these actions, which is aimed towards reduction of nitrogen oxides, is the use of a gas recirculation system. Nowadays an external EGR systems are most commonly used. They operation mainly consists on supplying a precisely specify portion of the fumes to the inlet manifold. Such a process is beneficial in terms of chemical reaction taking place in the cylinder due to the fact that the exhaust gas as the inert gas does not participate in the combustion process also have higher specific heat than air thereby significantly reduce the combustion temperature. In consequence less of oxygen reacts with nitrogen which results in limitation of $\mathrm{NO}_{\mathrm{x}}$ emission. Additionally the exhaust gases recirculation promotes evaporation of the fuel and the oxidation of unburned hydrocarbons [2]. In the case of the use of EGR in a multi-cylinder internal combustion engine, the most important factor is to supply charge for individual cylinders of the same composition in order to achieve a similar combustion process. The decisive influence on it has the shape of the intake manifold and the position of the EGR valve. This article presents the results of numerical computation of the charges formed in a symmetrical intake manifold with a centrally-placed EGR valve.

\section{Characterization of numerical investigations}

The investigation was performed on a intake manifold with the EGR which was a member of turbocharged, two-liter, sixteen-valve diesel engine with the designation 2.0 TDI BKD of Volkswagen Group. The default drive unit was equipped with a single EGR valve at the 
inlet of the intake manifold in such a way that the direction of flow of the exhaust valve was perpendicular to the main air supply channel.
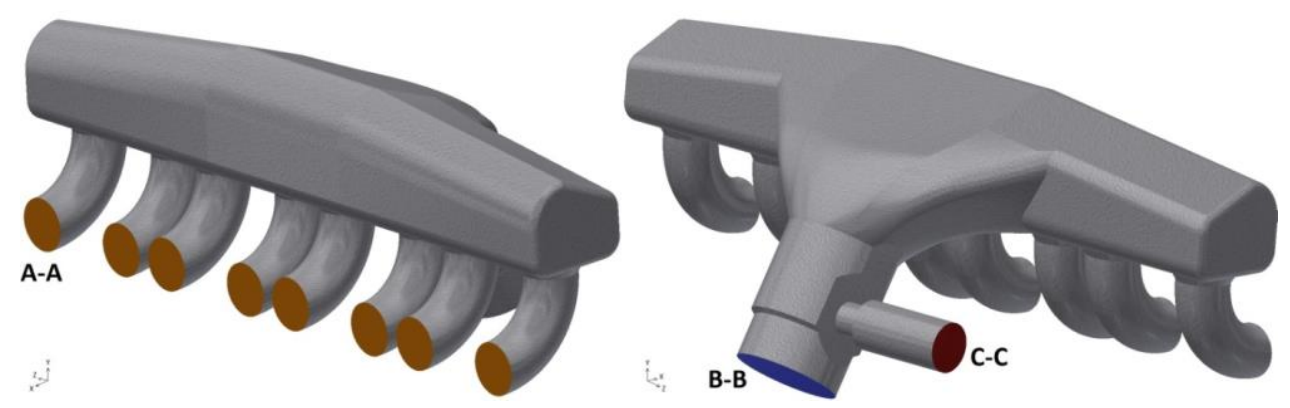

Fig. 2. Model of the intake manifold internal volume from the EGR valve designed for the flow rate numerical analysis.

Figure 2 shows the 3D model of the intake manifolds internal volume and the EGR valve marked cross sections: $A-A$ manifolds outlet ducts, $B-B$ of the air inlet, the $C-C$ the gas inlet to the EGR valve. In order to inspect the creation of the charge and its distribution in the intake manifold a flow simulations were performed for each pair of channels feeding a single cylinder. Simulations were performed for two cases of extreme speeds and two positions of EGR valve ranging $1 \mathrm{~mm}$ and $4 \mathrm{~mm}$, characterizing the degree of the exhaust gas flow. The process of the charge development and its distribution within the inlet manifold was verified by serous of CFD flow simulation, performed for each pair of ducts feeding single cylinder. Simulations were executed for two cases of extreme speeds and two positions of EGR valve - i.e. $1 \mathrm{~mm}$ and $4 \mathrm{~mm}$, characterizing the degree of the exhaust gas flow.

The analysis of the charge development in the intake manifold with the involvement of exhaust gas from the EGR valve was performed with aid of the finite volume method using ANSYS FLUENT 15.0. All the analyzed cases were dissolved in 300-350 iterations of the steady state flow with use of the k-epsilon turbulence model. The boundary conditions indicated flow rate of the inlet manifold and the inlet gas of the EGR valve. The individual speed values $v_{s}$ are calculated from equations (1) and (2).

where:

$$
Q=\frac{V_{s} \cdot n \cdot \eta_{V}}{2}\left[\frac{m^{3}}{s}\right]
$$

$Q\left[\frac{m^{3}}{s}\right]$ - volumetric flow rate

$V_{s}\left[\mathrm{~m}^{3}\right]$ - swept volume,

$n\left[\frac{o b r}{s}\right]$ - rotation speed

$\eta_{v}[-]$ - coefficient of the cylinder filling

$$
v=\frac{4 \cdot Q}{\pi \cdot d^{2}}\left[\frac{m}{s}\right]
$$

where:

$v\left[\frac{m}{s}\right]$ - gas flow rate

$d[m]$ - the diameter of the inlet duct 
Values for extreme speeds achieved for air $\left(v_{\text {air }}\right)$ and exhaust gases $\left(v_{\text {exh }}\right)$ corresponding to the extreme values of revolution speeds (i.e. $800 \mathrm{rpm}$ and $3000 \mathrm{rpm}$ ), for the inner diameter of intake manifold of $d=0.05 \mathrm{~m}$ are $v_{\text {air }(\min )}=2 \mathrm{~m} / \mathrm{s}$ and $v_{\text {air }(\min )}=7.5 \mathrm{~m} / \mathrm{s}$ in the case of air flow, whilst the extreme speeds of exhaust gases flow are $v_{\text {exh }(\min )}=8.7 \mathrm{~m} / \mathrm{s}$ and $v_{\text {exh(min) }}=32 \mathrm{~m} / \mathrm{s}$. Additional parameters determining the virtual flow conditions was the temperature of individual gases. For the air ambient temperature was assumed to $T_{p}=300 \mathrm{~K}$ while the exhaust gases temperature was $T_{s}=450 \mathrm{~K}$. The composition of charge formed in the manifold was dependent on the volume fraction of air and exhaust gases. The parameters characterizing the air were imported from Ansys Fluent, while the exhaust gases were defined as the percentage of nitrogen $-72 \%$, carbon dioxide $-14 \%$, and water vapor $-14 \%$. The characteristics of the gas parameters required for the calculations are shown in Table 1.

Table 1. Characterization of gas used to calculate.

\begin{tabular}{|c|c|c|}
\hline \multirow{2}{*}{ Parameter } & \multicolumn{2}{|c|}{ Value } \\
\cline { 2 - 3 } Density & $1.225 \frac{\mathrm{kg}}{\mathrm{m}^{3}}$ & $1.366 \frac{\mathrm{kg}}{\mathrm{m}^{3}}$ \\
\hline Specific heat & $1006.43 \frac{\mathrm{J}}{\mathrm{kg} \cdot \mathrm{K}}$ & $1146.46 \frac{\mathrm{J}}{\mathrm{kg} \cdot \mathrm{K}}$ \\
\hline Thermal conductivity & $0.0242 \frac{\mathrm{W}}{\mathrm{m} \cdot \mathrm{K}}$ & $0.0213 \frac{\mathrm{W}}{\mathrm{m} \cdot \mathrm{K}}$ \\
\hline Viscosity & $1.7894 \mathrm{e}^{-05} \frac{\mathrm{kg}}{\mathrm{m} \cdot \mathrm{s}}$ & $1.4834 \mathrm{e}^{-05} \frac{\mathrm{kg}}{\mathrm{m} \cdot \mathrm{s}}$ \\
\hline Molar mass & $28.966 \frac{\mathrm{kg}}{\mathrm{kmol}}$ & $28.84 \frac{\mathrm{kg}}{\mathrm{kmol}}$ \\
\hline
\end{tabular}
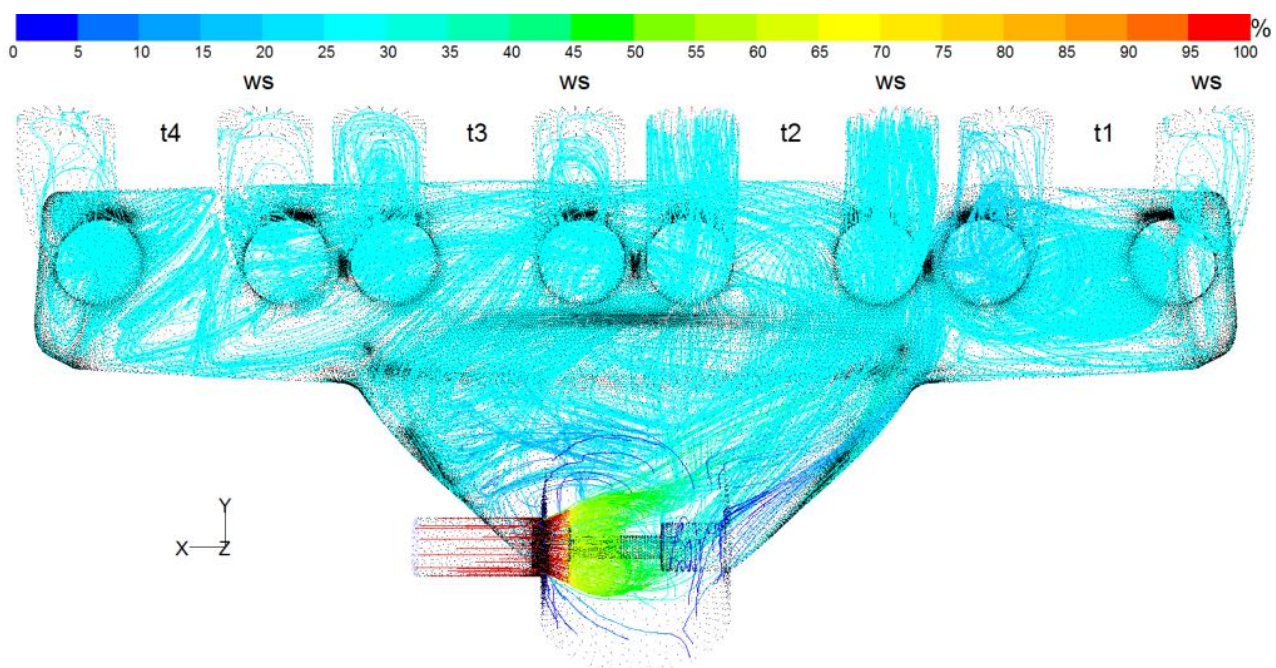

Fig. 3. Charge flow through the intake manifold with streamlines corresponding to percentage share of exhaust gas for channels supplying a second cylinder, for $v_{\text {air }(\min )}=7.5 \mathrm{~m} / \mathrm{s}, v_{\text {exh }}$ (min) $=32 \mathrm{~m} / \mathrm{s}$, the opening of the EGR valve $1 \mathrm{~mm}$.

Figure 3 and Figure 4 shows an example of the results in the form of flow streamlines representing percentage share of exhaust gases flowing through the intake manifold channels supplying the second cylinder with following boundary conditions: 
$v_{\max }=7.5 \mathrm{~m} / \mathrm{s}, v_{\text {smax }}=32 \mathrm{~m} / \mathrm{s}$, and the opening of the EGR valve of $1 \mathrm{~mm}$ and $4 \mathrm{~mm}$. Notation $t 1, t 2, t 3$ and $t 4$ corresponds to charge passing into the cylinder through the open duck pair at given time $t$ for the sequence of first, second, third and fourth cylinder. Moreover, the denotation $w s$ indicates the outlet channels of the manifold associated with swirl vane of the engine head.

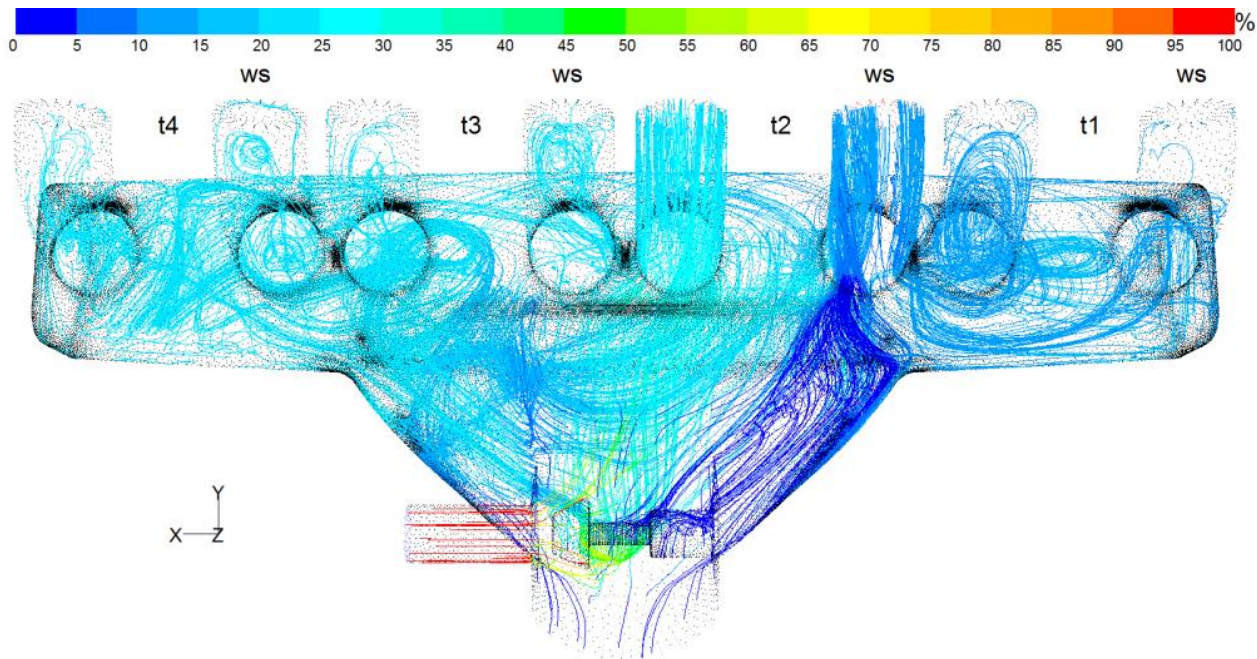

Fig. 4. Charge flow through the intake manifold with streamlines corresponding to percentage share of exhaust gas for channels supplying a second cylinder, for $v_{\text {air }(\min )}=7.5 \mathrm{~m} / \mathrm{s}, v_{\text {exh }(\min )}=32 \mathrm{~m} / \mathrm{s}$, the opening of the EGR valve $4 \mathrm{~mm}$.

For each of these cases the charge formed in the intake manifold is not uniform and its degree depends on the permeability of the EGR valve. The results of calculations for the case of Figure 3 illustrate that the lift of the valve disc at a height of $1 \mathrm{~mm}$ is very good in terms of mixing of the exhaust gases with flowing air. This is due to the increase in the speed of the exhaust gas flowing out of the EGR valve, thereby generating high charge motion above valve plate. The speed increase caused by the reduction of the area of movement, which is the side surface of the truncated cone formed by the valve head and valve-seat. For the case of Figure 4, the lift of the valve equal to $4 \mathrm{~mm}$, there is a significant deterioration in the mixing of the two gases. The reason for the decrease in speed of the exhaust gas flowing out of the increase in the surface area of a side of a truncated cone, which for this case is greater than the surface of gas flow through supply duck. With the decrease in the exhaust gas velocity there is a deviation of the air stream due to perpendicularly directed flow of exhaust gases as well as a small degree of mixing.

Figure 5 shows a cumulative summary of numerical computation of the charge development within a given ducts of the intake manifold under statical condition in terms of percentage distribution of the exhaust gases. Chases from the subpoints $a$ and $b$ were computed for $1 \mathrm{~mm}$ lift of the EGR valve, whereas the $c$ and $d$ for $4 \mathrm{~mm}$ lift of the EGR valve. 


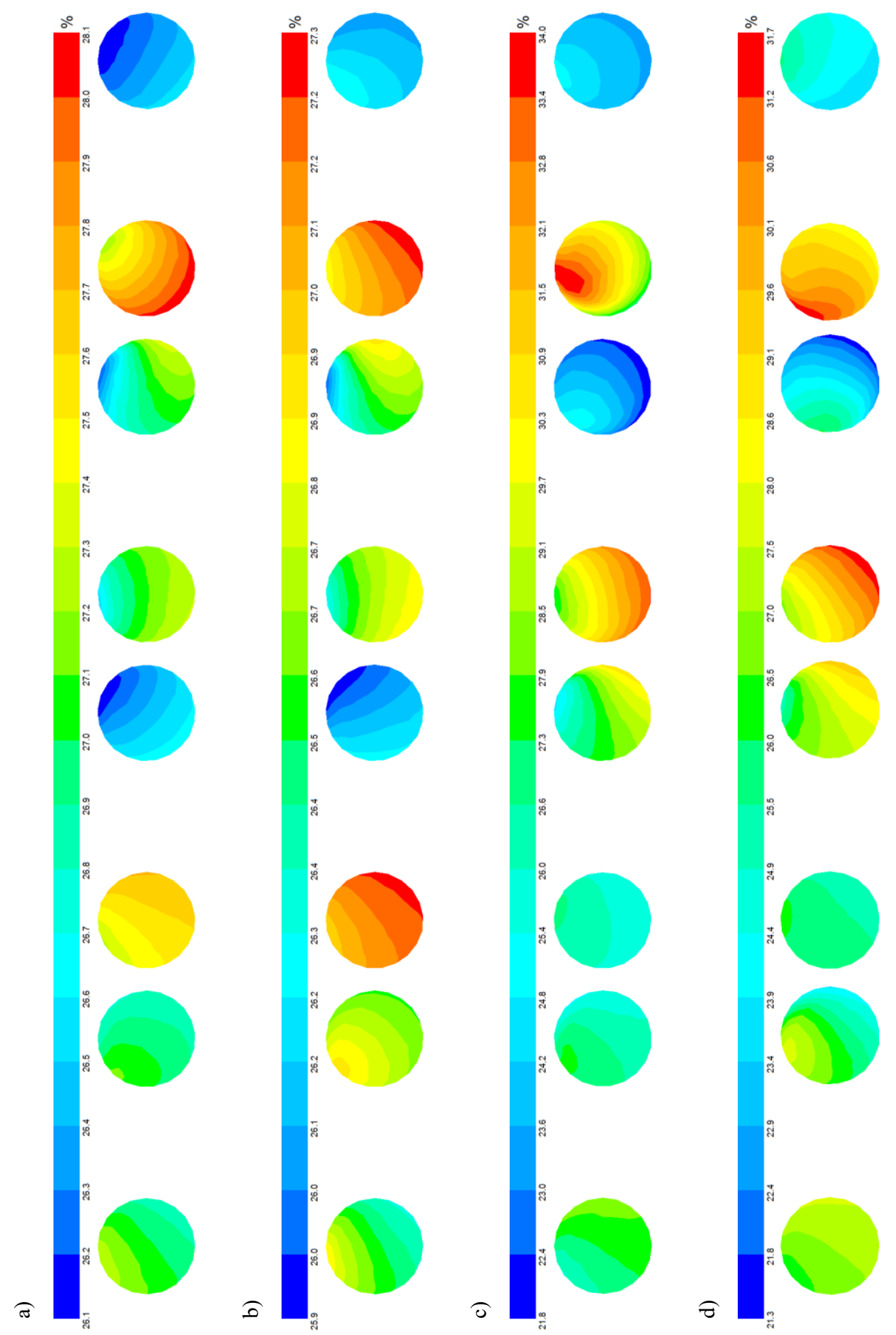

Fig. 5. The percentage of exhaust gas channels in the manifold: a) the EGR valve lift of $1 \mathrm{~mm}$, $\left.v_{\text {air }(\min )}=2 \mathrm{~m} / \mathrm{s}, v_{\operatorname{exh}(\min )}=8.7 \mathrm{~m} / \mathrm{s}, \mathrm{b}\right)$, the EGR valve lift of $1 \mathrm{~mm}, v_{\text {air }(\max )}=7.5 \mathrm{~m} / \mathrm{s}, v_{\operatorname{exh}(\max )}=32 \mathrm{~m} / \mathrm{s}$, c) the EGR valve lift $\left.4 \mathrm{~mm} v_{\text {air }(\min )}=2 \mathrm{~m} / \mathrm{s}, v_{\operatorname{exh}(\min )}=8.7 \mathrm{~m} / \mathrm{s}, \mathrm{d}\right)$ the EGR valve lift $4 \mathrm{~mm}$ $v_{\text {air }(\max )}=7.5 \mathrm{~m} / \mathrm{s}, v_{\text {exh }(\max )}=32 \mathrm{~m} / \mathrm{s}$. 
Moreover each case of the valve lift was considered for minimal and maximal velocity of the gases exiting the system. The minimal velocity of air $v_{\text {air }(\min )}$ and exhaust gases $v_{\text {exh }(\min )}$ were calculated for the cases $a$ and $c$ and maximal velocity of air $v_{\text {air }(\max )}$ and exhaust gases $v_{\text {exh }(\max )}$ for the cases $b$ and $d$. For a detailed analysis, a separate scale for the minimum and maximum values for each visualization was defined.

Simulations showed that the composition of the charge delivered to the individual intake channels of each cylinder is not identical. This phenomenon occurs independently of engine speed and EGR valve opening. mass flow of the gases obtained during the CFD computation allowed to calculate their average percentage share contained in the charge. In both cases of the EGR valve opening at 800 and $3000 \mathrm{rpm}$ the average percentage share of exhaust gas was $27 \%$. From Figure 5 it follows that in the initial phase of charge development there was a stratification of the individual components, which was uniformed during the flow to the cylinder through the intake manifold, the head channels and the intake valve. Therefore, obtaining the same mixtures within the ducts of a single intake manifold is dependent on an identical percentage share of individual gases.

This relationship is not met for any of the pending cases. For comparison, it can be assumed that the calculated average share of exhaust gas is $100 \%$ and on that basis determine the average percentage of the uneven distribution in the ducks for individual cases. The read value of the share fumes from Figure 5 are given in Table 2.

Table 2. Percentage uneven distribution of exhaust gases between the outlet duckts of the intake manifold.

\begin{tabular}{|c|c|c|c|c|c|}
\hline $\begin{array}{c}\text { Rotation speed } \\
{[\mathbf{r p m}]}\end{array}$ & EGR valve opening [mm] & $\mathbf{t 4}$ & $\mathbf{t 3}$ & $\mathbf{t 2}$ & $\mathbf{t 1}$ \\
\hline 800 & 1 & 0.37 & 4.07 & 0.74 & 5.37 \\
\hline 3000 & 1 & 0.93 & 5.37 & 0.56 & 3.52 \\
\hline 800 & 4 & 2.41 & 6.85 & 25.93 & 26.48 \\
\hline 3000 & 4 & 2.96 & 7.41 & 22.22 & 17.26 \\
\hline
\end{tabular}

Based on these results it can be concluded that the closed valve provokes the best mixing of the two gases, and the largest divergence occurs for ducks $t 3$ and $t 1$ - reaching up to $5.37 \%$. In the case of valve opening unevenness increases having the highest value for ducks $\mathrm{t} 1$ and $\mathrm{t} 2$ reaching a maximum value of $26.48 \%$ for the duck $t 1$. This is due to the stratification of the charge. The stream of exhaust gases and air flows almost rectilinearly to the duct - Figure 4 . The best mix of gases, regardless of the speed and the opening of the EGR valve, exist for the $t 4$ pair of ducts. This is due to increased concentration of air flow in the vicinity of the open valve head, which further promotes the formation of a homogeneous mixture.

\section{Conclusion}

The use of a single exhaust gas recirculation valve in an air supply system to a symmetric inlet manifold results in an uneven percentage share of exhaust gas in the direct duct as well as swirling (ws). In consequence the loads in the individual cylinders has different distribution of exhaust and air in its volume, which results in a different fuel combustion process and therefore, the useful torque obtained from each cylinder. In the case of a higher percentage of exhaust gas in the direct channel than the swirling one, a self-ignition delay and quenching of the flaring flame can occur as a result of lowering the temperature in the central portion of the charge containing a higher concentration of the exhaust gases. As a result, the reduction of nitrogen oxide emissions, with the simultaneous increase of carbon monoxide and Solid particles occurs. An additional factor which enhances uneven 
concentrations of toxic compounds between cylinders of multi-cylinder engines is the different degree of filling with the fresh load. Confirmation of this fact is carried out on an engines test rig using the intake manifold in which the emission of toxic compounds was measured with engaged and disengaged EGR valve. Figure 6 compares the emission of nitrogen oxides of the tested drive unit for $60 \mathrm{Nm}$ load and rotational speeds from 1000 to $2200 \mathrm{rpm}$
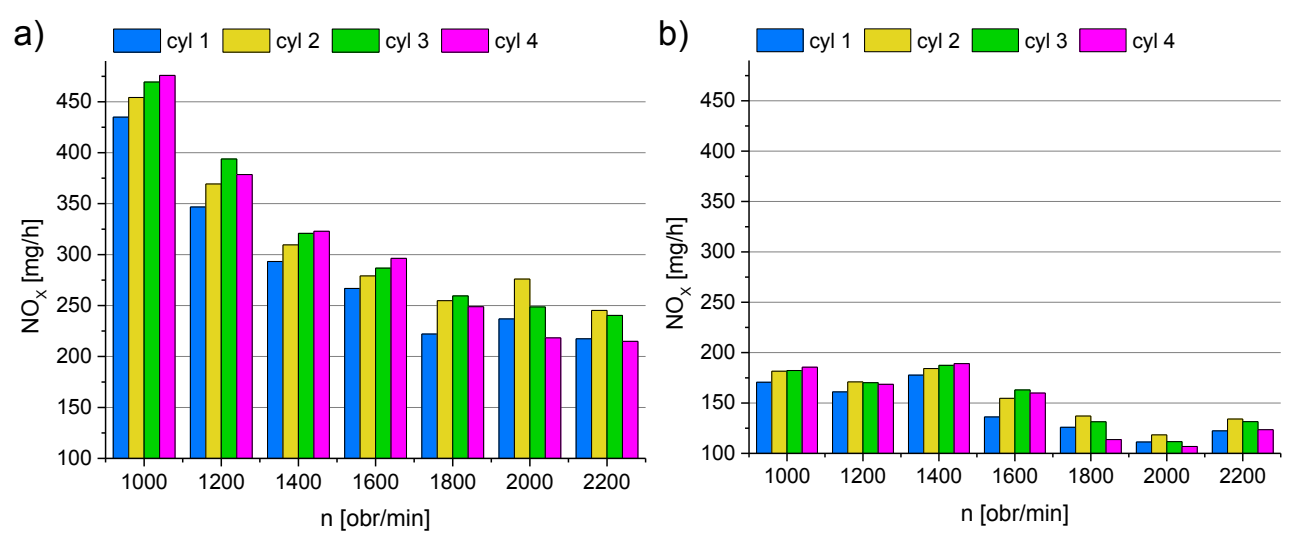

Fig. 6. Nitrogen oxide emissions from individual engine cylinders for a $60 \mathrm{Nm}$ load at: a) EGR valve disabled, b) EGR valve activated.

A solution to compensate the emissions of toxic compounds between cylinders may be the use of selective enrichment of individual loads with exhaust gases by the use of four separate EGR valves whose control could use the electronic crankshaft speed measurement system. The choice of selective percentage of exhaust gas would be based on the measurement of crankshaft acceleration that occurs during successive strokes that determine the correctness of the combustion process.

\section{References}

1. A. Bocheńska, C. Bocheński, MOTROL 7, 15-23 (2005)

2. K. Krakowian, A. Kaźmierczak, A. Górniak, R. Włostowski, KONES 19, 2 (2012)

3. Z. Sroka, (Oficyna Wydawnicza Politechniki Wrocławskiej, 2013) 